\title{
INSTITUCIONES HISTÓRICAS Y CAMBIO POLÍTICO: EL RESTABLECIMIENTO DE LA GENERALITAT DE CATALUÑA (1977)
}

HISTORICAL INSTITUCIONS AND POLITICAL CHANGE: THE RESTORATION OF THE GENERALITAT OF CATALONIA (1977)

\author{
Carlos González Martínez \\ Universidad de Valladolid
}

Entregado el 21-8-2015 y aceptado el 6/6/2016

\begin{abstract}
Resumen: El restablecimiento de la Generalitat ha sido considerado como uno de los episodios claves del relato político de la Transición. Las negociaciones entre Josep Tarradellas y Sánchez-Terán, unidas a los contactos anteriores entre Gobierno y president, así como el acuerdo de Perpiñán con los partidos catalanes, han sido interpretados por la historiografía como respuestas a un anhelo de la sociedad catalana en el tiempo político que se abrió tras la muerte del general Franco. Ahora bien, hasta la fecha se ha hecho poco hincapié en una visión histórica más amplia que supere el ámbito temporal de la Transición. El propio Real Decreto-ley 41/1977 hace referencia al decreto de 1938 por el que se derogaba la Generalitat. Nos encontramos, por tanto, con el único texto que reconoce una institución republicana, una cuestión poco abordada por la historiografía. De igual manera, tampoco se han aportado explicaciones convincentes de por qué, a diferencia de lo acaecido con la Generalitat, no se restablecieron otras instituciones republicanas existentes al comienzo de la Transición. Trataremos de dar respuesta a estas cuestiones a partir de testimonios de prensa, el archivo personal de Sánchez-Terán, las memorias de los principales políticos catalanes y entrevistas con algunos de los protagonistas.
\end{abstract}

Palabras clave: Transición Española; Generalitat de Cataluña; Autonomías; Josep Tarradellas; Adolfo Suárez; Salvador Sánchez-Terán 


\begin{abstract}
The reestablishment of the Generalitat has been considered as a key episode of the spanish politic during the Transition. The negotiation between Josep Tarradellas and Sánchez-Terán, in addition to the previous contacts between Goverment and Generalitat's president and Perpiñán's agreement with catalonian parties, have been interpreted as a reaction of a catalonian society desire during the political time which was opened after General Franco's death. Nevertheless, until now, it has been made little effort to get a larger historic view to overtake the temporal moment of the Transition. The own Royal Decree-law 41/1977 makes reference to the decree of 1938 by which the Generalitat was revoked. We are, therefore, in front of the only one text which recognizes a republican institution, a very little studied question. In the same way, convincing explanations about why, unlike of what ocurred with the Generalitat, other republican institutions were not reestablished at the beginning of the Transition, have not been provided. We will try to answer those questions using press testimonies, Sánchez-Terán personal files, personal memories of the main catalonian politicians and interviews with some other important actors.
\end{abstract}

Key words: Spanish Transition to democracy, Generalitat of Catalonia, Autonomies, Josep Tarradellas, Adolfo Suárez, Salvador Sánchez-Terán. 


\section{Introducción}

El 24 de octubre de 1977, Josep Tarradellas tomaba posesión como presidente de la restablecida Generalitat. Con su «Ciutadans de Catalunya, ja sóc aquí!» ponía fin a casi cuatro décadas en el exilio y a más de año y medio de contactos con los primeros gobiernos de la Monarquía. Tanto por el simbolismo como por las aplicaciones prácticas del acuerdo plasmado en el Real Decreto-ley 41/1977 de 29 de septiembre, este acontecimiento debe tenerse como uno de los momentos clave de la historia contemporánea catalana. Ahora bien, las consecuencias del retorno de Tarradellas, considerado por numerosos protagonistas e historiadores como uno de los grandes consensos de la Transición, no se limitaron solo a Cataluña, sino que afectaron, con el tiempo, a toda la organización territorial y política del Estado.

El restablecimiento de la Generalitat y el reconocimiento de Josep Tarradellas como su presidente suponía, en primer lugar, establecer un vínculo entre la nueva etapa histórica que se abría en España y su pasado republicano. El régimen político de finales de los años setenta, heredero en cierta medida del Estado del 18 de julio, aceptaba como legal una institución abolida por el franquismo y representada por un sucesor de Lluís Companys. Sin duda, esto aportaba un mayor grado de credibilidad al mensaje reformista y democratizador del Gobierno de Adolfo Suárez, ya fortalecido de por sí con la aprobación de la Reforma Política y la celebración de las elecciones del 15 de junio.

El segundo elemento a destacar es el papel de la Monarquía, representada por Juan Carlos I, en varias fases del proceso. En esos primeros meses de reinado, los catalanes fueron testigos de cómo un heredero de $\mathrm{Fe}$ lipe V, el monarca que abolió sus instituciones históricas a comienzos del siglo XVIII, respaldaba la recuperación de éstas en 1977. Por vez primera se reconocía la Generalitat bajo el reinado de los Borbones. En definitiva, la importancia histórica del retorno de Josep Tarradellas como su presidente no puede limitarse al contexto de la Transición, sino que ha de estudiarse con una perspectiva de casi tres siglos.

El tercer y último elemento a destacar del Real decreto-ley es su íntima relación con las autonomías. Si bien hubo que esperar a diciembre de 1978 para que el Estado pudiese denominarse autonómico, el restablecimiento de la Generalitat abrió el periodo de las preautonomías, que se construyeron en muchos casos según el modelo catalán. Por tanto, mientras Josep Tarradellas y Sánchez-Terán negociaban la devolución a Cata- 
luña de una parte importante de su historia, abrían, quizás sin saberlo, una vía legal para el futuro de la organización territorial del país.

A lo largo de las siguientes páginas se explica cómo se gestó el retorno de Josep Tarradellas a Cataluña, así como las alternativas para encauzar el hecho catalán que, en esos meses, plantearon otros actores políticos de relevancia. En su mayoría son cuestiones sobradamente estudiadas, si bien determinados acontecimientos han permanecido al margen de la historiografía existente. Además, existen algunos puntos del proceso que no han sido bien aclarados hasta la fecha. Para ello, además de en la bibliografía existente, este artículo se basa en los fondos documentales del archivo personal de Salvador Sánchez-Terán, del Arxiu Josep Tarradellas y en entrevistas a algunos de los protagonistas de esos hechos. Estos objetivos se abordan de forma cronológica, tratando en todo momento de situar el restablecimiento de la Generalitat dentro de un contexto más amplio, el de la Transición.

\section{El hecho catalán ante un tiempo nuevo}

Si bien las negociaciones que hicieron posible la aprobación del Real decreto-ley 41/1977 tuvieron lugar tras las primeras elecciones democráticas, para una mejor comprensión de los acontecimientos que rodearon al restablecimiento de la Generalitat de Cataluña es necesario retroceder a 1975. Desde su exilio en Saint-Martin-le-Beau, el honorable Josep Tarradellas veía llegado el momento de restablecer la institución por el presidida $^{1}$. Sin embargo, esa oportunidad que se abría precisaba dar un paso al frente, adelantarse a los acontecimientos y a los planes del Gobierno para Cataluña. De esta manera, el 1 de diciembre el president lanzaba su primer mensaje a los catalanes. Un plan de transición basado en la reconciliación nacional que, con la unidad de las fuerzas políticas y sociales de

1 TARRADELLAS, Josep, «Ja sòc aquí». Recuerdo de un retorno, Planeta, Barcelona, 1990, p. 22: «Intuía que no sería fácil lograr que los nuevos dirigentes del Estado aceptasen el restablecimiento de la Generalitat como paso previo a la colaboración de Cataluña en la obra común de España. Quise adelantarme a los hechos, hacer pública mi voluntad de crear un organismo político pactado con todas las fuerzas catalanas y articulado con la Generalitat a fin de constituirnos en interlocutores ineludibles a la hora de intervenir en la solución de nuestros problemas y también en los generales de España». 
Cataluña, llevase al restablecimiento de la Generalitat ${ }^{2}$. La actuación común de todos ellos les permitiría aparecer ante el Estado como una fuerza negociadora válida e ineludible en el camino hacia el cambio político. Esto debía llevar, en opinión de Tarradellas, a la inclusión de la institución que el representaba dentro del programa reformista del Gobierno ${ }^{3}$.

El mensaje del president fue de alguna forma recogido por los partidos nacionalistas, quienes constituyeron, a finales de diciembre de 1975, el Consell de Forçes Polítiques ${ }^{4}$. Precisamente en su acta fundacional se hacía referencia tanto a la figura de Josep Tarradellas como a la necesidad de restablecer la Generalitat ${ }^{5}$. El paso dado por los políticos catalanes hizo posible una primera ronda de reuniones con el president durante los días 10 y 11 de abril de 1976 en el hotel PLM Saint-Jacques de París ${ }^{6}$. Estos encuentros sirvieron para acercar posturas entre ambas partes, así como para establecer un compromiso en torno a la unidad de acción reclamada por Tarradellas cuatro meses atrás ${ }^{7}$. De esta manera, desde los mismo inicios de la Transición, la oposición catalana en bloque exigía el restablecimiento de las instituciones derogadas en 1939:

2 Ibid:: «...tres condiciones fundamentales: la amnistía total, el restablecimiento de la Generalitat de Cataluña y las elecciones constituyentes».

${ }^{3}$ PUJOL I SOLEY, Jordi, Historia de una convicción. Memorias (1930-1980), Destino, Barcelona, 2007, p. 275: «Tarradellas conocía y admiraba la figura y la obra de De Gaulle, y desde que se levantaba hasta que se iba a dormir sólo tenía una preocupación: mantener viva la Generalitat a base de repetirse constantemente que él era su presidente. Lo sustentaba una intuición en la que nadie creía pero que resultó cierta: que cuando en España se produjese el cambio político los catalanes se aferrarían a la Generalitat. Que él saldría al balcón del Palau de la Generalitat anunciando "Ja sóc aquî"».

${ }^{4}$ PREGO, Victoria; Así se hizo la Transición, Plaza\&Janés, Barcelona, 1995, p. 397: «Las reivindicaciones de este organismo unitario son, en primer lugar, autonomistas. El punto inicial de su programa es el restablecimiento de un gobierno provisional de la Generalitat de Cataluña, cuya representación sigue manteniendo viva desde el exilio el honorable Tarradellas, y la recuperación de las condiciones de autonomía del estatuto de 1932».

5 TARRADELLAS, Josep, op. cit., p. 26: «El punto sexto de la declaración fundacional del Consejo de Fuerzas Políticas aludía al papel de la Generalitat y de su Presidente en el proceso político que se iniciaba. Era la primera vez que un organismo unitario de la lucha clandestina establecía la necesidad de contar con el apoyo de las instituciones catalanas, pero subsistía el peligro de que fuese un simple recurso retórico».

6 «Una visión de Catalunya desde el exilio», Diario de Barcelona , 23/4/1976.

7 TARRADELLAS, Josep, op. cit., p. 49: «El balance del encuentro fue positivo. Se aceptó una política de amplia unidad catalana como condición para la constitución de un gobierno provisional de la Generalitat, así como actuar unitariamente en todo lo que guardase relación con España, bien fuera el Gobierno, bien las plataformas de oposición». 
«El Consell de Forçes Polítiques de Catalunya ha expresado nuevamente al presidente de la Generalitat, de acuerdo con sus bases programáticas, la irrevocable decisión de luchar por la instauración en Catalunya de las instituciones de la Generalitat y de los principios configurados en el Estatuto de 1932, hoy reivindicados por la gran mayoría de los catalanes. Los reunidos han considerado que en el proceso hacia la formación de un gobierno provisional de la Generalitat de Catalunya hay que tener en cuenta la totalidad de las fuerzas políticas, sociales y del movimiento obrero de Catalunya, y en especial de la Assemblea de Catalunya» $^{8}$.

El encuentro en el PLM Saint-Jacques de París inauguró un periodo de entendimiento entre Josep Tarradellas y el Consell de Forçes Polítiques que, si bien no exento de discrepancias, permitió que la oposición catalana se presentara como una unidad ante el Gobierno de España. Una única voz que tenía, como reclamación fundamental, el restablecimiento de la Generalitat. La condición sine qua non del primer mensaje del president se había cumplido. Había llegado, pues, el momento de buscar un entendimiento con Madrid.

La primera visita de una delegación gubernamental a Saint-Martinle-Beau se produjo el 14 de febrero de $1976^{9}$. Se trata de un episodio que ha sido prácticamente ignorado por la historiografía, bien por desconocimiento o por considerarlo intrascendente en el proceso que llevó al restablecimiento de la Generalitat. No en vano, el fracaso del proyecto reformista del primer Gobierno de la Monarquía impidió que tuviera lugar un hipotético segundo contacto con Tarradellas, dejando ese primer encuentro sin repercusiones políticas. Ahora bien, sin perder de vista que fue la llegada de Adolfo Suárez al poder lo que permitió abordar la cuestión catalana con la profundidad y seriedad que requería, hay dos aspectos que deben ser destacados de aquella reunión. El primero de ellos, sin duda el

8 SÁNCHEZ-TERÁN, Salvador; De Franco a la Generalitat, Planeta, Barcelona, 1988 , p. 85.

9 TARRADELLAS, Josep, op. cit., p. 34: «Me expusieron que el gobierno no quería rupturas, sino aperturas o reformas, dentro de las cuales existían posibilidades de encauzar de manera positiva el problema de Cataluña. Deseaban conocer mis ideas y propósitos para informar al gobierno y al rey al respecto. Insistí en que el primer problema era la reconciliación de todos los españoles, la superación del franquismo con un nuevo régimen en el que estuviesen representadas todas las fuerzas políticas y sociales sin excepción. Para ello eran necesarias la amnistía, la legalización de todos los partidos, la democratización de la vida pública» 
más importante, es que la iniciativa no partió ni del presidente del Gobierno, Carlos Arias, ni de su ministro de la Gobernación, Manuel Fraga, sino de La Zarzuela. Juan Carlos I tenía especial interés en conocer la postura del presidente de la Generalitat antes de iniciar su primera visita oficial a Cataluña como Rey. Sería excesivo afirmar que ya por entonces el monarca se planteaba la posibilidad de restablecer las instituciones catalanas, pero parece evidente que valoraba la figura de Tarradellas, elevándolo al estatus de interlocutor válido.

El segundo punto a tener en cuenta es que, por el mero hecho de autorizar la reunión, el Gobierno de España reconocía por primera vez la importancia política de la Generalitat, lo cual no debe llevarnos a pensar que, por aquel entonces, estuviera dispuesto a restablecerla. De hecho, Carlos Arias no mostró ningún interés en los preparativos de la visita a Saint-Martin-le-Beau, y mucho menos en el contenido de las conversaciones. Simplemente se limitó a dar el visto bueno a petición de La Zarzuela. Del mismo modo, Manuel Fraga, a pesar de ocuparse de organizar el encuentro por medio de Antoni Bofarrull y Antoni Navarro, y de enviar dos colaboradores suyos, como eran Luis Santiago de Pablos y Manuel Milián, tenía unos planes para Cataluña muy distintos a la construcción autonómica ${ }^{10}$. La prueba de la escasa confianza que tenía el ministro de la Gobernación en la reunión con Tarradellas es que no informó del encuentro a dos de sus principales colaboradores en Cataluña, Salvador Sánchez-Terán y Juan Antonio Samaranch ${ }^{11}$.

Apenas unos días después de la reunión en Saint-Martin-le-Beau, el 20 de febrero de 1976, Manuel Fraga llevaba al Consejo de Ministros la constitución de una Comisión de Régimen Administrativo Especial para

10 SÁNCHEZ-TERÁN, Salvador; De Franco...op. cit., p. 20: «En cuanto a Cataluña, tras un análisis histórico en profundidad, Fraga, que ha mantenido relación con políticos catalanes en los últimos meses, opina que no se debe restablecer el Estatuto del 32, pero que el hecho catalán, cuya importancia resalta, es preciso abordarlo con seriedad y rigor, y por ello piensa constituir una comisión mixta que proponga los planteamientos esenciales de un régimen especial para Cataluña».

11 Entrevista a Salvador Sánchez-Terán, 24 de febrero de 2015: «Desconocía hasta ahora la existencia de esa reunión en época de Carlos Arias. No se de dónde pudo partir la iniciativa, aunque creo que el principal interesado en conocer las opiniones de Tarradellas era don Juan Carlos. Desde luego Fraga no tenía ningún interés en restaurar la Generalitat. Él tenía su propio proyecto, en el que estaba trabajando la Comisión de Régimen Especial. En mi opinión, si no nos comentó nada a Samaranch y a mí, es porque no daba valor esa reunión». 
Cataluña ${ }^{12}$. Su principal cometido era establecer las bases de un proceso de descentralización administrativa que, una vez se llevara a cabo la reforma política, podría desembocar en un régimen estatutario ${ }^{13}$. Esto suponía cerrar las puertas al restablecimiento de la Generalitat y al retorno de Josep Tarradellas como presidente de la institución. No nos detendremos a explicar en qué consistieron los trabajos de la Comisión, pero es interesante señalar al menos tres cuestiones. La primera es la existencia, a comienzos de 1976, de un proyecto gubernamental para dar respuesta a la cuestión catalana. Procedimiento que, como hemos indicado, se construía como alternativa al restablecimiento de la Generalitat. Otro aspecto a destacar es la prolongación de esta vía más allá de la crisis gubernamental que llevó a Adolfo Suárez a la presidencia ${ }^{14}$. A pesar de la ausencia de Manuel Fraga en el ejecutivo, la Comisión de Régimen Especial continuó sus trabajos y presentó sus conclusiones al Consejo de Ministros a comienzos de $1977^{15}$. Por último, aunque Tarradellas consideraba que un proyecto de esas características no daba respuesta a las necesidades de

12 Orden de 13 de abril (BOE de 13-12-1976), por el que se designan los vocales que han de formar parte de la Comisión para el estudio de un régimen especial para las cuatro provincias catalanas.

${ }_{13}$ Proyecto de Decreto por el que se crea una comisión para el estudio de la implantación de un régimen especial para la provincia de Barcelona, Archivo de Salvador Sánchez-Terán, Carpeta: «De Franco a la Generalitat. Cap. 7», Documento 525, p. 1: «La Diputación Provincial de Barcelona ha elevado una moción al Ministerio de la Gobernación en el sentido de solicitar al Gobierno la constitución de una Comisión que estudie la implantación de un régimen administrativo especial para la provincia de Barcelona que permita, en un futuro próximo, institucionalizar la región catalana en la línea de la declaración programática del Gobierno sobre una organización institucional de las regiones. El Gobierno Civil de Barcelona ha informado favorablemente la citada moción elevada por la Diputación Provincial».

${ }^{14}$ SÁNCHEZ-TERÁN, Salvador; De Franco...op. cit., p. 58.

15 Conclusiones de la comisión para el estudio de un régimen especial de las cuatro provincias catalanas, Archivo de Salvador Sánchez-Terán, Carpeta: «De Franco a la Generalitat. Cap. 28», Documento 993, pp. 15-16: «Esas actuaciones inmediatas concretas se concretan en lo siguiente: a) Constitución de una mancomunidad de servicios, tan amplia como sea posible, entre las cuatro diputaciones provinciales (...) b) Transferencia de las funciones, obras o servicios del Estado a las diputaciones provinciales o a la Mancomunidad, desarrollando el contenido de la base 48 de la ley de Bases del Estatuto del Régimen Local (...) c) Que se determine de acuerdo con el contenido del artículo 30 de la ley del Suelo, que la Mancomunidad sea la entidad competente para la redacción del Plan Director Territorial de Coordinación con ámbito que abarque al de las cuatro provincias catalanas (...) d) Implantación progresiva de la cooficialidad de la lengua catalana...» 
Cataluña, era plenamente consciente de que constituía la principal amenaza para sus planes de restablecimiento de la Generalitat ${ }^{16}$.

En definitiva, los preliminares de la que comúnmente es conocida como «Operación Tarradellas» se desarrollaron en tres episodios distintos, todos ellos dentro del periodo que va de la muerte del general Franco a la dimisión de Carlos Arias. El primero de ellos es el acuerdo entre el presidente de la Generalitat y las fuerzas políticas catalanas para formar un frente común en lo relativo a las reivindicaciones autonomistas. El segundo, la voluntad de Juan Carlos I por establecer contacto con Josep Tarradellas, que contrasta con el escaso interés del Gobierno. Por último, precisamente en lo que se refiere al Ejecutivo, un proyecto descentralizador del Ministerio de la Gobernación materializado en la constitución de la Comisión de Régimen Administrativo Especial.

\section{El juego político de Adolfo Suárez}

Como hemos indicado anteriormente, la crisis de gobierno del verano de 1976 no afectó al proyecto de descentralización administrativa puesto en marcha por Manuel Fraga. De esta manera, a finales de noviembre, la Comisión remitía, al Gobierno y a los gobernadores civiles de las cuatro provincias catalanas, un proyecto de ley en el que se concretaban las instituciones básicas del régimen especial: el Consejo General de Cataluña - encargado de redactar el Estatuto-, la Comisión de Acción Regional y la Mancomunidad ${ }^{17}$.

16 TARRADELLAS, Josep, op. cit., p. 42: «Todo el asunto de la Comisión del Régimen Especial fue una desafortunada iniciativa política, condenada de antemano al fracaso por estar sujeta a los límites estrechísimos que imponía el gobierno Arias».

17 Conclusiones de la comisión para el estudio de un régimen especial de las cuatro provincias catalanas, Archivo de Salvador Sánchez-Terán, Carpeta: «De Franco a la Generalitat. Cap. 28», Documento 993, pp. 17-18: «1. El Consejo General de Cataluña, integrado por los representantes en Cortes - senadores y diputados - de las cuatro provincias catalanas y por tres representantes de cada una de las diputaciones provinciales que integran la región. 2. La Comisión de Acción Regional, integrada por los Presidentes y dos Diputados provinciales de cada una de las Diputaciones. Esta Comisión sirve de enlace entre los entes locales provinciales y el Consejo, de apoyo permanente a éste y de instrumento coordinador de la acción del Consejo y de las acciones provinciales. 3. La Mancomunidad de Cataluña. Es un órgano de carácter eminentemente prestador de servicios y coordinador de las competencias atribuidas a las Diputaciones provinciales, pudiendo asumir en su caso sin mengua de la personalidad jurídica de las mismas - si así se acuerda por ellas - la totalidad de esas competencias». 
Este hecho, unido al aparente respaldo que, en su visita oficial a Barcelona, concedió el presidente Suárez a los trabajos de la Comisión, convenció a Tarradellas de que debía pasar a la acción ${ }^{18}$.

A diferencia de lo acaecido en febrero de 1976, en esta ocasión fue el presidente de la Generalitat quien tomó la iniciativa. Su intermediario fue Manuel Ortínez, empresario catalán que mantenía una buena relación de amistad con Alfonso Osorio ${ }^{19}$. No tuvo dificultades, por tanto, para ser recibido por el vicepresidente en el palacio de la Moncloa y presentarle su propuesta:

18 Discurso de Adolfo Suárez con motivo de su visita oficial a Barcelona (2012-1976), Archivo de Salvador Sánchez-Terán, Carpeta: «De Franco a la Generalitat. Cap. 28», Documento 1004, pp. 10-12: «Tenemos ya un primer trazado del camino a seguir, los estudios de la Comisión del Régimen Especial de las cuatro provincias catalanas. Son unos estudios realistas, en cuanto han considerado como punto de partida la situación política actual de España y en cuanto que, partiendo de los más significativos datos históricos, perfila las posibilidades de futuro de una Cataluña, cuya potenciación se proyecta hacia la común empresa española. Sus planteamientos parten de la afirmación de su personalidad histórica, pero, asimismo, ni desconocen ni olvidan que esa comunidad nacional fue el fruto de la unión en una idea común de los grandes pueblos que la constituyen (...). El razonado estudio de un Régimen Especial para Cataluña que la Comisión presenta es base importante y válida para ser sometida a la consideración de las futuras Cortes. Pero creo también que algunas de sus conclusiones pueden constituir una opción para el Gobierno y otras podrán convertirse en realidad en función del desarrollo de la Ley de Bases del Estatuto de Régimen Local. Por la trascendencia de las proposiciones presentadas y por la propia naturaleza del tema que abordan, el Gobierno asume el compromiso de estudiarlas con el detenimiento y profundidad que merecen»

19 SÁNCHEZ-TERÁN, Salvador; De Franco...op. cit., p. 282: «Ortínez hace una exposición clara y clásica sobre el papel de Cataluña en la historia de España, sobre los muchos errores que en Madrid se han cometido por la incomprensión del hecho catalán y de la importancia decisiva que tiene para la Monarquía y para la democracia que se dé una adecuada solución a la cuestión catalana. Todas esas cosas - viene a decir - de la descentralización, de las mancomunidades, del Consell General, etc., no sirven para nada y es eludir el problema. "La Generalitat - afirma Ortínez - es considerada por los catalanes como la cristalización de su personalidad, en el bien entendido que ésta no es sinónimo de independencia o de separatismo porque yo, catalán, me siento tan español y con el mismo derecho que tú, castellano; pero no quiero que me tuteles, sino que me comprendas y que me respeten como se respetan los hermanos bien avenidos de una misma madre"». 
«Restablecer la Generalitat, invitar a Tarradellas a venir a Madrid, visitar al Rey, aceptar la Monarquía y la unidad de España, nombrarle presidente de la Generalitat, negociar con éste desde el Gobierno las funciones de la Generalitat» ${ }^{20}$.

Osorio informó inmediatamente a Suárez, quien, tras consultarlo con varios centristas catalanes, se mostró abierto en un primer momento a restablecer la Generalitat ${ }^{21}$. No obstante, el presidente mantenía sus reservas en torno a la figura de Tarradellas. Consideraba que a una persona de esa edad, tras tantos años fuera de España, le resultaría sumamente difícil adaptarse a la situación del país y que, por tanto, podría poner en peligro todo el proyecto ${ }^{22}$. Suárez sugirió una operación realizada en torno a Jordi Pujol, que contaba con la confianza de Rodolfo Martín Villa, ministro de la Gobernación, y Salvador Sánchez-Terán, gobernador civil de Barcelona. Finalmente cedió ante la insistencia, por parte de Ortínez, de respetar la legitimidad histórica que ostentaba Tarradellas $^{23}$. El presidente se comprometió, por tanto, a consultarlo con el Rey y a enviar un emisario a Saint-Martin-le-Beau.

El segundo encuentro de Josep Tarradellas con un representante del Gobierno español tuvo como protagonista al teniente coronel Andrés Casinello, que acudió a Saint-Martin-le-Beau en compañía de Manuel Ortínez. Sus impresiones de casi cuatro horas de entrevista quedaron

${ }^{20}$ Tarradellas en Madrid, Archivo de Salvador Sánchez-Terán, Carpeta: «De Franco a la Generalitat. Cap. 37», Documento 1213, p. 4.

${ }^{21}$ Ibid., p. 5: «Ortínez va a Saint-Martin-le-Beau a hablar con Tarradellas y Osorio lo hace con Suárez. Este, al principio, oye a Osorio como si le hablara en chino. Pero, después de consultar el tema con los centristas catalanes Carlos Güell, Carlos Sentís y Juan Mas Cantí, que le hablan positivamente, empieza a considerar la posibilidad. Su fino instinto político le dice que si Tarradellas y él se entienden, de una tacada el centro se asienta en Cataluña. Y de paso se soluciona un contencioso secular».

22 Entrevista a Salvador Sánchez-Terán, 24 de febrero de 2015.

23 OSORIO, Alfonso, Trayectoria política de un ministro de la Corona, Planeta, Barcelona, 1980, p. 357: «La conversación fue distendida y fácil. Adolfo Suárez preguntó si "para todo eso no era mejor Jordi Pujol", a lo que Ortínez contestó que no, porque Tarradellas era un catalán universal, "un todoterreno", fue la expresión, y Pujol un catalán de partido. No obstante, Suárez insistió un poco más sin convicción, alegando que el gobernador de Barcelona, Salvador Sánchez-Terán, y Rodolfo Martín Villa eran bastante "pujolistas"». 
reflejadas en un completo informe que fue entregado al presidente ${ }^{24}$. A su vez, Adolfo Suárez autorizó los contactos entre Osorio y Ortínez para que, sin ningún compromiso por parte del Gobierno, sentaran las bases para el posible restablecimiento de la Generalitat y el retorno de Tarrade$\operatorname{llas}^{25}$. Ahora bien, todo esto no suponía la paralización de los trabajos en torno al Régimen Especial iniciados durante la etapa de Manuel Fraga. El presidente mantenía el respaldo a dos iniciativas incompatibles, a la espera de decidir cuál de las dos era la opción más conveniente.

La elección se tomó definitivamente el 18 de febrero de 1977, día en el que el Consejo de Ministros comenzó a estudiar la constitución de un Consejo General de Cataluña. Ese respaldo a los trabajos realizados por

${ }^{24}$ El «Informe Casinello», Archivo de Salvador Sánchez-Terán, Carpeta: «De Franco a la Generalitat. Cap. 37», Documento 1213, p. 5: «Tarradellas quiere la institución, la Generalitat. No ofrece ahora nada, ni recomendar el sí al referéndum. Pero, frente a otros, se niega a constituir un Gobierno en el exilio. No quiere tomar partido en una situación en que cada grupo quiere una cosa distinta. Es decir, tiene concepción de hombre de Estado. El Rey se afirma ante él como una realidad perdurable y el Ejército como una necesidad de entendimiento pacífico..., pero los que van a verle apareciendo como sus seguidores, no. Puede que sea la razón por la que busca ser de verdad presidente de la Generalitat de Cataluña sin más poderes de los que tiene Samaranch y con los mozos de escuadra como una forma de hacer sensible su poder moral. No quiere que el Gobierno pacte con los grupos. Quiere ser el intermediario, el protagonista. Piensa que su autoridad modera las posturas, que su institución salvará el enfrentamiento entre Cataluña y el resto de España. Ofrece un camino: después del referéndum, intercambiar programas, exponer los puntos de vista del Gobierno sobre Cataluña y exponer él su ideal de lo catalán en el marco de lo español y alcanzar el entendimiento en el punto medio. Quiere seguir hablando, negociando, pero con el Gobierno».

${ }^{25}$ Ibid., p. 283: «Primero: el presidente de la Generalitat acatará públicamente al Rey, a la unidad de España y manifestará su respeto al ejército.

Segundo: el arreglo jurídico administrativo a adoptar antes de fin de enero próximo se podría basar en:

a) Derogar el Decreto de 1938 anulando el régimen autonómico de Cataluña, con objeto de reunir en torno a la Corona a todos los pueblos que constituyen la realidad nacional, respetando sus características particulares e institucionales históricas y tradicionales, como es el caso de la Generalitat de Cataluña.

b) De acuerdo con la ley de Régimen Local se constituirá, a petición de las diputaciones respectivas, la mancomunidad de la cuatro diputaciones catalanas que, en atención a los antecedentes históricos tradicionales, se llamará Generalitat y disfrutará de los derecho que prevé la misma ley de Régimen Local.

c) A propuesta de las diputaciones el Gobierno nombrará un presidente de la Generalitat sin poderes ejecutivos expresos, pero con autoridad para actuar con funciones representativas y negociadoras dentro de lo que la ley en vigor permite.

d) Las instituciones, estructura y alcance de la autonomía de Cataluña lo fijarán las Cortes por el procedimiento que ellas mismas dictaminen». 
la Comisión de Régimen Administrativo Especial suponía dejar en un segundo plano la opción Tarradellas ${ }^{26}$. El principal motivo que llevó a Suárez a interrumpir las negociaciones entre Osorio y Ortínez fue su convencimiento personal de que la vía presentada por la Comisión para dotar a Cataluña de un régimen de autogobierno resultaba menos problemática. El restablecimiento de la Generalitat, además de suponer una operación compleja, podía desviar la atención del Gobierno y de la opinión pública a una cuestión que se alejaba del objetivo prioritario: preparar las primeras elecciones democráticas ${ }^{27}$. Para justificar su decisión, contaba con el aval de los resultados obtenidos en Cataluña con motivo del referéndum, así como con la buena sintonía existente entre el gobernador civil y los grupos nacionalistas ${ }^{28}$. En esas circunstancias, el presidente consideró más sencilla la creación de un organismo, en lugar de recurrir a la Generalitat, ya que esto último obligaba a su vez a plantearse «la cuestión política del País Vasco, con el terrorismo de fondo, y con unas perspectivas nada esperanzadoras $»^{29}$. Por todas estas razones, y sin llegar a descartar en ningún momento la opción de Tarradellas, Adolfo Suárez prefirió tomar la vía del Régimen Especial, con la esperanza de, una vez celebradas las elecciones, poder situar al frente del Consejo General de Cataluña al centrista Juan Antonio Samaranch - finalmente el candidato de la UCD fue Carlos Sentís - o, en su defecto, a Jordi Pujol ${ }^{30}$.

${ }^{26}$ SÁNCHEZ-TERÁN, Salvador; De Franco...op . cit., p. 283: «Suárez no dio vía libre a este proyecto de negociación y el asunto quedó congelado, a pesar de la insistencia de Osorio en la importancia política de la operación».

27 Ibid., p. 184: «Suárez estaba volcado en la transición política a la democracia, tras el éxito de la ley de reforma política. Su preocupación esencial era elaborar unas normas electorales, aceptadas por la oposición que le permitieran convocar elecciones generales. Abordar la cuestión catalana era desviarse de su objetivo prioritario y estaba "fuera de tiempo"».

${ }_{28}$ POWELL, Charles T., España en democracia, 1975-2000. Las claves de la profunda transformación de España, Plaza \& Janés, Barcelona, 2001, p. 184: «Sin embargo, los buenos resultados del referéndum en Cataluña hicieron que Suárez perdiera interés en el ilustre exiliado, y la posterior incorporación de Pujol a la comisión de los nueve - que irritó profundamente a Tarradellas, defensor a ultranza de que las negociaciones entre la oposición catalana y el gobierno se realizaran por separado-, pareció abrir una vía más directa».

29 SÁNCHEZ-TERÁN, Salvador; De Franco...op. cit., p. 284.

30 Tarradellas en Madrid, Archivo de Salvador Sánchez-Terán, Carpeta: «De Franco a la Generalitat. Cap. 37», Documento 1213, p. 6: «Se trasladó esta propuesta a Suárez, pero éste congeló el asunto ante el ofrecimiento de que Samaranch y un grupo de alcaldes formarían un grupo político que respaldaría la opción de centro». 
Hubieron de llegar las elecciones del 15 de junio de 1977 para que la actitud de Moncloa hacia Tarradellas diera un giro de ciento ochenta grados. Desde los primeros días de la campaña se hizo evidente la importancia de la Generalitat, omnipresente en los discursos de los principales líderes nacionalistas. Así lo percibió el candidato catalán de la UCD, Carlos Sentís, que temía una capitalización de la figura del president por parte de la oposición:

«Lo que significaría un descalabro electoral irreparable. Manuel Ortiz, gobernador civil de Barcelona, alertó a Rodolfo Martín Villa del asunto para que lo traspasase a Suárez. El Gobierno debe jugar ahora la baza de Tarradellas. Suárez recelaba todavía. Osorio y Ortínez siguen insistiendo, pero el presidente, según el primero, le había dicho: «Lo siento, Alfonso, pero no acabo de ver qué puede hacer Tarradellas en Cataluña; es demasiado viejo. Además, todo eso de los mozos de escuadra , como símbolo de poder, suena a opereta». Tuvieron que llegar los resultados para que Suárez viera que los catalanes habían votado masivamente a los partidos que respaldaban a Tarradellas. Y Suárez cambió radicalmente de parecer» ${ }^{31}$.

Si bien el presidente no supo interpretar de manera acertada el ambiente autonomista que se respiraba durante la campaña, entendió qué debía hacer una vez se hicieron públicos los resultados. Los grupos de izquierdas, encabezados por el PSC y el PSUC, habían superado ampliamente a las coaliciones de centro-derecha, el Pacte Democràtic de Jordi Pujol y la UCD, encabezada en Cataluña por Carlos Sentís. Esta situación le generaba un contratiempo, ya que en lugar de entenderse con uno de estos dos políticos, circunstancia deseada en Moncloa, debería hacerlo con el líder de los socialistas catalanes, Joan Reventós ${ }^{32}$. De ahí que, frente a una negociación de la autonomía con la izquierda catalana, tomara fuerza la alternativa de retomar el diálogo con Josep Tarradellas.

31 Ibid.

32 SÁNCHEZ-TERÁN, Salvador; La Transición... op . cit., p. 194-195: «Parece claro que el Gobierno hubiera deseado negociar con Carlos Sentís o Jordi Pujol, pero resultaba evidente y destacada la ventaja electoral del PSC-PSOE, e ineludible, por tanto, la adjudicación de un liderazgo a Reventós. En ese momento y ante la alternativa Reventós o Tarradellas, es cuando el Presidente del Gobierno comienza a considerarse con seriedad las posibilidades de retorno del exiliado presidente». 


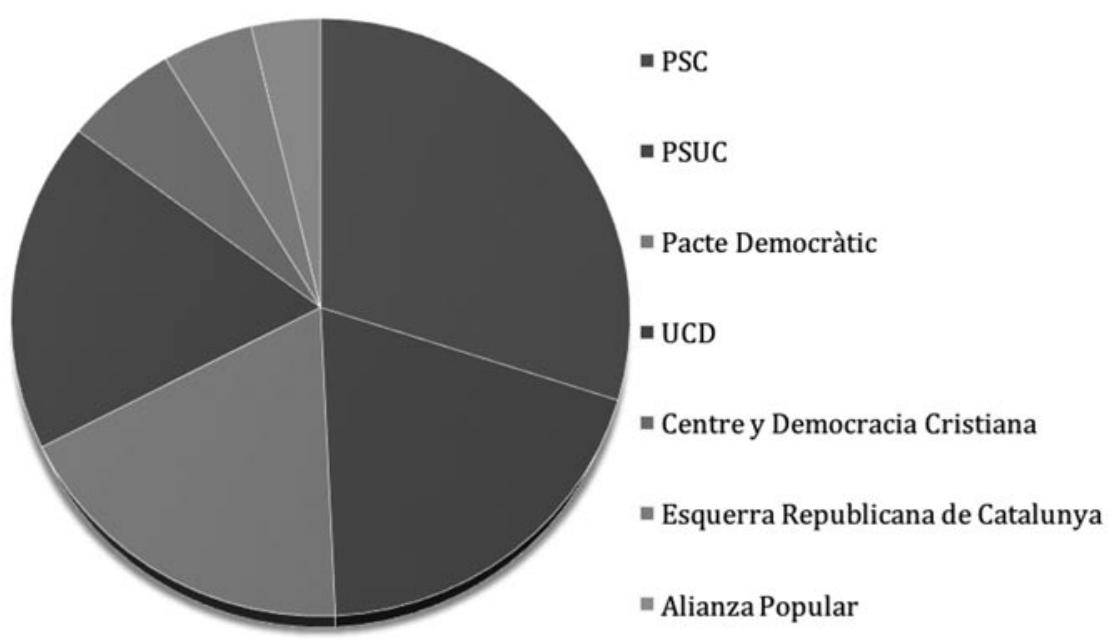

\begin{tabular}{|c|c|c|}
\hline Partidos Políticos & Porcentaje de votos & Escaños \\
\hline PSC-PSOE & $28.51 \%$ & 15 \\
\hline PSUC & $18.33 \%$ & 8 \\
\hline Pacte Democràtic & $17.22 \%$ & 11 \\
\hline UCD & $17.05 \%$ & 9 \\
\hline Centre y Democracia Cristiana & $5.78 \%$ & 2 \\
\hline Esquerra Republicana de Catalunya & $4.65 \%$ & 1 \\
\hline Alianza Popular & $3.55 \%$ & 1 \\
\hline
\end{tabular}

Resultados en Cataluña de las elecciones generales del 15 de junio de 1977.

Fuente: SÁNCHEZ-TERÁN, Salvador, De Franco a la Generalitat, Barcelona, Planeta, 1988 , p. 273.

El 22 de junio, durante una reunión con Rodolfo Martín Villa, Manuel Ortiz y Carlos Sentís, el presidente del Gobierno anunció su voluntad de 
retomar el proyecto iniciado en su momento por Osorio y Ortínez ${ }^{33}$. Suárez se decantaba definitivamente por el restablecimiento de la Generalitat y encargaba a Carlos Sentís, cuya amistad con Tarradellas era bien conocida, concretar los detalles de su desplazamiento a Madrid, donde debía mantener una entrevista con él y otra con el Rey ${ }^{34}$. El diputado catalán de la UCD se puso en contacto con Saint-Martin-le-Beau para comunicar la decisión del Gobierno y concretar una fecha para el viaje. También se ocupó de informar a Manuel Ortínez, quien se trasladó a París el 26 para acompañar a Tarradellas en esas jornadas decisivas ${ }^{35}$. Al día siguiente el president ponía rumbo a Madrid, dando inicio a un viaje que, no exento de contratiempos, abriría las negociaciones definitivas para el restablecimiento de la Generalitat de Cataluña.

Cabe distinguir, por tanto, tres etapas dentro del periodo que va desde la llegada de Adolfo Suárez al poder hasta la celebración de las primeras elecciones democráticas. En un primer momento, con la irrupción de Manuel Ortínez en escena, el Gobierno mantuvo abiertas dos posibles vías para encauzar la cuestión catalana. Una de ellas, la Comisión de Régimen Especial, heredara de la etapa de Carlos Arias, y la otra planteada, vía intermediario, por el propio Tarradellas. Sin embargo, a partir de febrero, entendiendo que el ejecutivo ya tenía demasiados frentes abiertos, el presidente optó por el que a su juicio era el camino menos problemático hacia la descentralización. Finalmente, los resultados de las elecciones del 15 de junio terminaron por convencer a Suárez de que había cometido un

33 ABELLA, Carlos, Adolfo Suárez, el hombre clave de la transición, Espasa, Madrid, 2006, p. 219: «Afortunadamente, según reconoce Sánchez-Terán, durante toda la campaña electoral el gobernador civil de Barcelona, Manuel Ortiz, había estado informando a Adolfo Suárez y a Rodolfo Martín Villa de la conveniencia de plantearse a fondo la opción Tarradellas, evocando de paso su veterana amistad que Carlos Sentís mantenía con Tarradellas. Y esta es la primera decisión que tomó el gobierno Suárez: pedirle a Carlos Sentís que se convirtiera en su interlocutor en el retorno de Tarradellas».

34 TARRADELLAS, Josep, op. cit., p. 100: «El mismo miércoles 22 se reunían en la Moncloa el presidente Suárez, el ministro Martín Villa, el diputado centrista por Barcelona Carlos Sentís y el gobernador civil de Barcelona Manuel Ortiz. En esta reunión se decidió mi viaje a Madrid. Adolfo Suárez optaba por negociar directamente conmigo, volvía a tomar un camino que había ofrecido buenas perspectivas (...) Volvió a los planteamientos de antes de las elecciones: restablecer la Generalitat en un clima de concordia y como camino por el que Cataluña aceptaba la monarquía y pactaba con ella, al hacer posible ésta la recuperación de nuestras instituciones».

35 SÁNCHEZ-TERÁN, Salvador; De Franco...op. cit., p. 286. 
error subestimando la importancia que, para los catalanes, tenía una institución como Generalitat.

\section{Las negociaciones para el restablecimiento de la Generalitat}

El acuerdo que permitió restablecer las instituciones históricas catalanas comenzó a gestarse el 27 de junio de 1977, pasadas las siete de la tarde, en el palacio de la Moncloa. El primer encuentro entre Suárez y Tarradellas abrió un periodo de tres meses que condujo a la aprobación del Real decreto-ley 41/1977. Un proceso en el que participaron también los miembros de la Asamblea de Parlamentarios de Cataluña, y en la que desempeñó un papel fundamental Salvador Sánchez-Terán, hombre elegido por Adolfo Suárez para hacerse cargo de las negociaciones ${ }^{36}$. Por tanto, para una mejor comprensión de este episodio de la Transición, hemos de tener en cuenta la presencia de tres entes en el acuerdo: el Gobierno español, la Generalitat y los diputados elegidos en Cataluña con motivo de las elecciones del 15 de junio. Eso explica que, además de las reuniones entre Josep Tarradellas y Salvador Sánchez-Terán, tuvieran lugar encuentros de cada uno de ellos con los representantes de la Asamblea de Parlamentarios. Por tanto, si bien todo quedó reflejado de manera unitaria en el Real decreto-ley, lo más correcto es hablar de tres acuerdos.

No nos detendremos a explicar los pormenores de los contactos que, entre las tres partes, se produjeron a los largo de la negociación, pues es una cuestión ampliamente abordada por la historiografía y, en especial, en las memorias de Josep Tarradellas y Salvador Sánchez-Terán. Ahora bien, es necesario, al menos, resumir los principales hitos del proceso que llevó al restablecimiento de la Generalitat. En ese sentido, podemos distinguir cuatro escenarios bien diferenciados: el inicio de las negociaciones con motivo del viaje del president a Madrid en el mes de junio, el papel desempeñado por la Asamblea de Parlamentarios de Cataluña, la intervención de Salvador Sánchez-Terán como representante del Gobierno de Es-

36 ABELLA, Carlos, op. cit., p. 240: «...a primeros de agosto, y al terminar una de las primeras reuniones de UCD como partido político, Rodolfo Martín Villa le propuso a Salvador Sánchez-Terán - en presencia de Adolfo Suárez y por sugerencia de este- que se hiciera cargo de la negociación con Tarradellas, relatándole el detalle de las reuniones mantenidas por este con Suárez y el Rey e insistiéndole en que no había ningún acuerdo firme, solo la voluntad de restablecer provisionalmente la Generalitat». 
paña, y el acuerdo de Perpiñán entre los tres entes a los que nos hemos referido anteriormente.

El primero se produjo con motivo del viaje de Tarradellas a Madrid, en el que se entrevistó en dos ocasiones con Adolfo Suárez y en una con Juan Carlos I y Rodolfo Martín Villa. Es bien conocida la falta de entendimiento que reinó en el primer cara a cara entre Suárez y el president ${ }^{37}$. Sin embargo, el buen hacer del ministro de la Gobernación, unido al trato afable que el monarca dispensó Tarradellas en la recepción del 29 de junio, permitieron retomar las conversaciones con un aire renovado ${ }^{38}$. Así, el 1 de julio, presidente del Gobierno y de la Generalitat se encontraron de nuevo en Moncloa. De allí salió un principio de acuerdo, el llamado «Protocolo Suárez-Tarradellas», que fue hecho público al día siguiente ${ }^{39}$.

37 TARRADELLAS, Josep, op. cit., p. 116: «Empezó diciéndome lo que ya sabía: que su gobierno quería solucionar el problema de Cataluña tratándolo como un asunto de Estado, que por ello estaba dispuesto a pactar de acuerdo con las posibilidades de la legislación vigente y sin perjuicio de lo que más tarde aprobase el parlamento. Se mostraba dispuesto a una actuación de carácter gradual. Le contesté que todo eso me parecía muy bien pensado, pero que no contase conmigo para ninguna solución que no fuese el restablecimiento de la Generalitat (...) Adolfo Suárez no quería reconocer a la Generalitat en aquel momento. Yo quería que la reconociese. Me hizo todo género de ofrecimientos: la Mancomunidad A, la Mancomunidad B, el Gobierno Provisional C, el Consejo D... A cada propuesta yo le respondía que no. Me expuso los precedentes jurídicos de cada una de sus opciones, las disposiciones legales, las posibilidades administrativas. No daba mi brazo a torcer. Mis negativas lo exasperaron. Me ofrecía la presidencia de todo lo que tenía a mano, y yo la rechazaba. Adolfo Suárez no entendía nada».

38 Ibid., p. 139: «El jueves 30, el proceso negociador se encontraba totalmente desatascado gracias a la intervención del Rey».

39 Acuerdo del 2 de julio de 1977 publicado en el número 3 del Diari Oficial de la Generalitat de Catalunya, Archivo de Salvador Sánchez-Terán, Carpeta: «De Franco a la Generalitat. Cap. 37», Documento 1217, p. 3: «En las conversaciones entre el Presidente del Gobierno, D. Adolfo Suárez y el Honorable D. Josep Tarradellas, se han abordado cuantos temas afectan a la situación política y a las soluciones posibles para dotar a Cataluña de la necesaria autonomía en el marco de sus instituciones históricas acomodadas al tiempo presente. El régimen definitivo de la autonomía ha de ser establecido por las Cortes Españolas, y se espera que pueda ser facilitado mediante un procedimiento de negociación entre el Gobierno y los representantes elegidos, recientemente, en las cuatro provincias catalanas. Se ha tratado en las conversaciones, la necesidad de constituir, en el marco de la vida local, una fórmula transitoria que, apoyada en la legalidad vigente permita ir avanzando en la solución, desde ahora, de la voluntad de recuperar las instituciones seculares del pueblo catalán. La Ley de Bases del Régimen Local, posibilita la creación de divisiones territoriales distintas de la provincia, con lo que se puede restablecer la unidad institucional de Cataluña. Para crear 
Poco antes de abandonar Madrid, el president mantuvo un encuentro con los representantes de la Asamblea de Parlamentarios en el domicilio de Manuel Ortínez. El motivo era informarles del estado de las negociaciones tras sus entrevistas con Adolfo Suáre ${ }^{40}$. Los contactos entre Josep Tarradellas y los partidos políticos catalanes fueron muy intensos durante el mes de julio. Ambas partes volvieron a reunirse entre los días 4 y 7 en el hotel Sheraton de París, y el 29 en Sant Cebrià del Roselló ${ }^{41}$. El presidente de la Generalitat logró en estos encuentros alcanzar su objetivo: incorporar a los parlamentarios a la negociación mediante la constitución de una Comisión Negociadora que estuviera bajo su autoridad ${ }^{42}$. En definitiva, Josep Tarradellas buscaba, tanto mantener el frente común que venía

la institución representativa de Cataluña, es necesario la decisión asociativa de las cuatro provincias catalanas y la voluntad decidida del Gobierno, que no se demorará, pues está previsto concluir el texto articulado de la Ley de Bases, antes de finalizar el mes de julio. Dicha institución asumiría competencias atribuidas a las Diputaciones o al Estado. Ello permitiría restaurar la Generalidad como representación legal y reglamentar el régimen transitorio de la misma. Se precisó por parte del Presidente del Gobierno, en lo que mostró su conformidad el honorable Sr. Tarradellas, que las autonomías deben ofrecerse a todas las Regiones españolas sin que las formas concretas de las mismas hayan de ser uniformes, pues, en todo caso, han de respetarse las peculiaridades sociológicas e históricas de todos los pueblos españoles, dentro de la irrenunciable unidad de España».

40 PUJOL I SOLEY, Jordi, op. cit., p. 308: «Al día siguiente, sábado, Tarradellas convocó a la Assemblea de Parlamentaris Catalans en el domicilio madrileño de Manuel Ortínez, donde se alojaba el president. La Assemblea congregaba a los diputados catalanes de diferentes partidos y su misión consistía en unir fuerzas para defender la restauración de la Generalitat y su president, y abogar por el autogobierno de Cataluña. Nos reunimos Anton Cañellas, Joan Reventós, Josep Verde Aldea, Antoni Gutiérrez Díaz, Heribert Barrera, Miquel Roca, Josep Maria Cullell y yo».

41 TARRADELLAS, Josep, op. cit., p. 218: «El 29 se celebra en el salón de sesiones del ayuntamiento de San Cipriano del Rosellón la reunión del presidente con la Comisión Permanente de la Asamblea de Parlamentarios. El resultado principal es la constitución de una Comisión Negociadora encabezada por el presidente e integrada por seis parlamentarios elegidos por la Asamblea, que serán nombrados por el presidente en el Diario Oficial de la Generalitat».

${ }^{42}$ Constitución de la comisión negociadora, número 3 del Diari Oficial de la Generalitat de Catalunya, Archivo de Salvador Sánchez-Terán, Carpeta: «De Franco a la Generalitat. Cap. 37», Documento 1217, pp. 1-2: «Queda constituida, bajo la presidencia del presidente de la Generalitat, una comisión negociadora del restablecimiento inmediato de la Generalitat en el territorio de Cataluña y de la regulación de su régimen transitorio». 
defendiendo desde el año anterior, como evitar el uso partidista de su figura por parte de los distintos líderes políticos nacionalistas ${ }^{43}$.

El tercer escenario en el que se gestó el restablecimiento de la $\mathrm{Ge}-$ neralitat de Cataluña fue la serie de reuniones que mantuvieron Josep Tarradellas y Salvador Sánchez-Terán. Mientras el president y los parlamentarios catalanes alcanzaban un acuerdo, en Madrid el Gobierno también se preparaba para afrontar la inminente negociación. En los primeros días de agosto, al finalizar la sesión en que se aprobaron los estatutos provisionales de la UCD, Rodolfo Martín Villa, con el conocimiento de Adolfo Suárez, mantuvo una conversación privada Salvador Sánchez-Terán ${ }^{44}$. El ministro del Interior le propuso hacerse cargo de las negociaciones para el restablecimiento de la Generalitat de Cataluña: «me explicó en detalle las reuniones de Tarradellas con Suárez y con el Rey y el significado que el Gobierno daba a la declaración final. No había ningún acuerdo en firme y todas las posibilidades estaban abiertas. Ciertamente existía la voluntad de restablecer provisionalmente la Generalitat, pero sin prejuzgar nada el desarrollo futuro de la autonomía. Me correspondía hacer una propuesta razonable para el Gobierno y aceptable para Tarradellas y los parlamentarios catalanes; teniendo en cuenta los antecedentes históricos de la cuestión catalana, pero sobre todo pensando en el presente y en el futuro de la democracia española. Recibí, en resumen, un amplísimo margen de confianza de parte de Suárez y Martín Villa para enfocar la negociación de la forma y con el ritmo que considerara más oportuno» ${ }^{45}$.

En la elección de Sánchez-Terán pesaron, sin duda, los meses que pasó en Barcelona como gobernador civil de la provincia. Ese periodo no sólo le otorgó fama de buen negociador, sino que sirvió para generar

43 SÁNCHEZ-TERÁN, Salvador; De Franco...op. cit., p. 287: «A partir de su visita a Madrid y de la declaración final, la figura de Tarradellas adquiere una preponderancia absoluta en la negociación del restablecimiento de la Generalitat. En la diarquía presidenteAsamblea de Parlamentarios Catalanes, la iniciativa del Gobierno de dialogar con Tarradellas, centra en él todo el protagonismo y la capacidad de decisión».

${ }^{44}$ ABELLA, Carlos, op. cit., p. 240: «...a primeros de agosto, y al terminar una de las primeras reuniones de UCD como partido político, Rodolfo Martín Villa le propuso a Salvador Sánchez-Terán - en presencia de Adolfo Suárez y por sugerencia de este - que se hiciera cargo de la negociación con Tarradellas, relatándole el detalle de las reuniones mantenidas por este con Suárez y el Rey e insistiéndole en que no había ningún acuerdo firme, solo la voluntad de restablecer provisionalmente la Generalitat».

${ }^{45}$ SÁNCHEZ-TERÁN, Salvador; De Franco...op. cit., p. 288. 
un clima de confianza entre él y la oposición catalana ${ }^{46}$. Tanto a Suárez como a Martín Villa no se les escapaba que los parlamentarios elegidos en Cataluña desempeñarían un relevante papel en el proceso de restablecimiento de la Generalitat, de ahí la importancia de situar al frente de la negociación a un hombre que desde los primeros días de la Transición había logrado entenderse con ellos ${ }^{47}$. Por tanto, aunque Sánchez-Terán se reunió con Josep Tarradellas en calidad de consejero del presidente - cargo que ostentaba desde finales de julio de 1977-, lo realmente decisivo para su elección fue su condición de ex gobernador civil de Barcelona $^{48}$.

Las reuniones que, durante los días 10 y 11 de agosto, mantuvieron en el hotel Crillon sirvieron tanto para el conocimiento mutuo como para que tuviera lugar un intercambio de impresiones acerca de la forma que debía tomar el Real decreto-ley ${ }^{49}$. Sánchez-Terán acudió con un borrador for-

46 Entrevista a Salvador Sánchez-Terán, 5 de julio de 2012: «Claro, yo doy mucha importancia a la negociación con Tarradellas, pero el acuerdo de Perpiñán fue con todos los dirigentes políticos, todos. Era la primera vez que eso sucedía; fue el primer consenso de la Transición».

47 Entrevista a Rodolfo Martín Villa, 20 de junio de 2012: «En la primera llegada del presidente de la Generalitat a España, Salvador Sánchez-Terán había cesado de su cargo en Barcelona para poder presentarse a las elecciones de 1977, así que no me extrañaría nada que se enterase por la prensa de la llegada de Tarradellas a Madrid. Es en la segunda etapa cuando Salvador tomó las riendas de la operación y la llevó a buen puerto. Yo creo que dejarlo en sus manos fue una buena decisión de Adolfo Suárez, y, sin duda, su gran servicio político a la Transición fue ese».

48 Real Decreto 1963/1977, de 29 de julio, por el que se nombran consejeros del Presidente del Gobierno: «En virtud de los dispuesto en el artículo primero del Real Decreto mil seiscientos noventa y dos/mil novecientos setenta y siete, de once de julio, a propuesta del Presidente del Gobierno y previa deliberación del Consejo de Ministros en su reunión del día veintinueve de julio de mil novecientos setenta y siete. Vengo a nombrar Consejeros del Presidente del Gobierno a don Alfonso Osorio García, don José Ramón Lasuén Sancho, don Federico Mayor Zaragoza, don Salvador Sánchez-Terán Hernández, don Arturo Moya Moreno, don Lorenzo Olarte Cullen y don Leopoldo Calvo-Sotelo y Bustelo».

49 SÁNCHEZ-TERÁN, Salvador; De Franco...op. cit., pp. 290-291: «La primera sesión matutina, se dedicó a un mutuo conocimiento. Tarradellas y yo teníamos una amplia información sobre el otro interlocutor, pero en política ningún informe escrito puede sustituir al contacto personal. Las tres primeras horas en el hotel Crillon constituyeron un anecdotario histórico de tan alto interés, que siento no poder reproducirlo por razones de espacio. Tarradellas - gran conversador - habló del exilio, de la entrada de los alemanes en París, de sus consejos a Companys para evitar caer en manos de la Gestapo, de los últimos tiempos de la Generalitat, de la rebelión del $34 .$. , y se interesó por la realidad política española del momento, 
mado por ocho artículos, pero creyó conveniente escuchar en primer lugar la propuesta de Tarradellas ${ }^{50}$. Éste le entregó un documento que, bajo el título «Bases para un decreto-ley de restablecimiento provisional de la Generalitat de Cataluña», desarrollaba en diez puntos un programa aceptado en su mayoría por el representante del Gobierno ${ }^{51}$.

sobre todo los resultados electorales, el estilo del Gobierno Suárez y la composición de la UCD. Su asombro ante el escaso porcentaje de votos obtenido por don José María Gil Robles en Salamanca frente a nuestra candidatura de UCD fue enorme. Me hizo repetir dos veces las cifras. Su admiración hacia los grandes oradores de las Cortes de la República era grande. Él escuchaba absorto a los Besteiro, Ortega y Gasset, Azaña y Gil Robles. Una conclusión flotaba en nuestras mentes. Aquella España política que él vivió no tenía nada que ver con la actual. Y yo me preguntaba: ¿Será capaz este hombre, con casi ochenta años, de no ser prisionero de su pasado y asumir normalmente la nueva realidad».

50 ABELLA, Carlos, op. cit., p. 240: «Sánchez-Terán prefirió escuchar los planteamientos de sus interlocutores, en lugar de mostrar su decreto-ley. Tarradellas le entregó un documento titulado «Bases para un decreto-ley de restablecimiento provisional de la Generalitat de Cataluña», con el que Sánchez-Terán expresó su coincidencia general, pero rechazó los artículos que proponían que «la Generalitat asumiera la representación legal de Cataluña» y que "el Gobierno y la Administración de Cataluña durante el periodo transitorio corresponderían al president de la Generalitat"».

${ }^{51}$ Bases para un decreto-ley de restablecimiento provisional de la Generalitat de Cataluña, Archivo de Salvador Sánchez-Terán, Carpeta: «De Franco a la Generalitat. Cap. 38», Documento 1250: 1. Se restablece, con carácter provisional, la Generalidad de Cataluña hasta la entrada en vigor del régimen definitivo de la autonomía que se establezca por las Cortes.

2. La Generalidad asume la representación legal de Cataluña, que comprende el territorio de las provincias de Barcelona, Gerona, Lérida y Tarragona.

3. El Gobierno y administración de Cataluña durante el periodo transitorio corresponde al presidente de la Generalidad y a su Consejo de Gobierno.

4. Se nombra presidente de la Generalidad hasta la entrada en vigor del régimen definitivo de la autonomía de Cataluña al honorable Josep Tarradellas Joan.

5. El presidente de la Generalidad designará a los miembros del Consejo de Gobierno y fijará sus respectivas atribuciones.

6. Las Diputaciones Provinciales de Barcelona, Gerona, Lérida y Tarragona son órganos administrativos de la Generalidad de Cataluña.

7. Se crea en la Presidencia del Gobierno una Comisión Mixta de composición paritaria, que propondrá al Gobierno los acuerdos sobre transferencia a la Generalidad del ejercicio de funciones y actividades propias de la competencia del Estado, organismos autónomos o empresas públicas.

8. El real decreto ley entrará en vigor el mismo día de su publicación en el BOE.

9. Queda autorizado el ministro del Interior para dictar las disposiciones reglamentarias en ejecución del real decreto ley.

10. Queda derogada la ley decretada en 5 de abril de 1938». 
Después de dos semanas en las que cada una de las partes estudio la propuesta por separado, Sánchez-Terán y Tarradellas volvieron a encontrarse en París los días 26 y 27 de agosto ${ }^{52}$. En esta ocasión, el representante del Gobierno tomó inmediatamente la iniciativa, e hizo entrega a su interlocutor de dos documentos: el proyecto de real decreto-ley de restablecimiento de la Generalitat y nombramiento de Josep Tarradellas como su presidente ${ }^{53}$. Para su elaboración, además de todo el bagaje acumulado en las negociaciones anteriores, fue fundamental la reunión que pocos días atrás había mantenido Sánchez-Terán en Moncloa con Adolfo Suárez, Fernando Abril, Rodolfo Martín Villa y Manuel Clavero ${ }^{54}$. El primer texto constaba de nueve artículos y tres disposiciones finales, en donde se abordaban cuestiones como la personalidad jurídica de la Generalitat, su ámbito actuación, composición orgánica y atribuciones ${ }^{55}$. Por su parte, el nombramiento de presidente era bastante más sencillo:

52 SÁNCHEZ-TERÁN, Salvador; De Franco...op. cit., p. 293: «El 16 y 17 de agosto se reunían, en Saint-Martin-le-Beau, Tarradellas, su delegado en Cataluña, Frederic Rahola y la Comisión Negociadora - Benet, Gutiérrez, Pujol, Reventós, Sentís y Triginer- - Los parlamentarios hicieron notar su presencia e introdujeron en el documento de bases unas modificaciones esenciales. En el punto 3 añadieron que el presidente de la Generalitat y su Consejo de Gobierno "estarán asistidos por la Asamblea provisional. Esta Asamblea estará formada por el conjunto de diputados y senadores de las cuatro circunscripciones de Cataluña". En el punto 5, relativo al nombramiento y fijación de atribuciones de los miembros del Consejo de Gobierno, añadían, "con la aprobación de la Asamblea provisional"».

53 TARRADELLAS, Josep, op. cit., p. 221: «El 26 y el 27 de agosto tiene lugar en la habitación 420 del hotel Crillon parisino la segunda ronda de negociaciones entre el presidente Tarradellas y Salvador Sánchez-Terán. El delegado del gobierno español presenta el proyecto de real decreto-ley de restablecimiento de la Generalitat y el real decreto del nombramiento de Tarradellas como presidente de la institución».

54 ABELLA, Carlos, op. cit., p. 243: El 19 de agosto se celebró una reunión en la Moncloa, a la que asistieron el presidente, Martín Villa, Abril Martorell, Manuel Clavero y Salvador Sánchez-Terán, en la que este informó del curso de la negociación y en la que Manuel Clavero introdujo de nuevo su rechazo a un tratamiento privilegiado de Cataluña frente a las demás regiones, posición que hizo dudar a Suárez si no era mejor esperar a la elaboración de la Constitución - cuya negociación ya había comenzado-. Finalmente prevaleció el criterio de seguir adelante con el restablecimiento de una Generalitat provisional.

55 SÁNCHEZ-TERÁN, Salvador; De Franco...op. cit., pp. 296-297: «El artículo primero del texto legal restablecía «con carácter provisional la Generalitat de Cataluña, hasta la entrada en vigor del régimen de autonomía que pueda aprobarse por las Cortes». El segundo definía la personalidad jurídica de la Generalitat y su ámbito de actuación referido a las provincias de Barcelona, Gerona, Lérida y Tarragona. En el tercero se constituían como órganos de gobierno de la Generalitat, durante el período transito- 
«En virtud de lo dispuesto en los artículos $3 .^{\circ}$ y $4 .^{\circ}$ del decreto ley 41/1977, y a propuesta del presidente del Gobierno, se nombra presidente de la Generalidad de Cataluña a don Josep Tarradellas Joan» ${ }^{56}$.

El president leyó ambos documento con detenimiento y, si bien posteriormente mostró algunas objeciones al contenido del Real decreto-ley, no pudo ocultar su satisfacción por el resultado de la negociación:

«Estos textos suponen un paso muy importante para Cataluña y para España. Dé usted las gracias, en mi nombre, al presidente Suárez y a S. M. el Rey» 57.

rio, el presidente y el Consejo Ejecutivo. No había referencia, por tanto, a la Asamblea de Parlamentarios. El artículo fijaba que el nombramiento del presidente de la Generalitat se haría por decreto a propuesta del presidente del Gobierno. El quinto definía el Consejo Ejecutivo integrado por un número máximo de Consejeros, designados por el presidente y por los presidentes de las diputaciones catalanas. El presidente asignaría a los miembros del Consejo sus respectivas titularidades y atribuciones. No había condicionantes ni sometimiento a la conformidad de los parlamentarios. El artículo sexto, que fue el más debatido en todo el proceso posterior, decía en su redacción final: «Corresponde a la Generalitat, dentro del régimen jurídico, general y local vigente, las siguientes atribuciones:

a) La elaboración y aprobación de sus propias normas de régimen interior.

b) La coordinación de la actuación de las cuatro diputaciones provinciales, en cuanto afecte al interés general de Cataluña.

c) La gestión y administración de las funciones y servicios que le transfiera la Administración del Estado y las expresadas diputaciones. El Gobierno establecerá el procedimiento para realizar tales transferencias.

d) La propuesta al Gobierno de cuantas medidas afecten a los intereses de Cataluña».

e) Los artículos séptimo y octavo ya han sido transcritos en el apartado precedente y el noveno era el ritual que autorizaba al Gobierno el desarrollo normativo. Las tres disposiciones finales se referían a la entrada en vigor del decreto ley y a la derogación de ley de la Jefatura del Estado de 8 de abril de 1938 -que suprimió el Estatuto y la Generalidad tras la toma de Barcelona en la guerra civil - y del decreto 382/77 de 18 de febrero, relativo a la creación del Consell General de Catalunya».

${ }^{56}$ Borrador del decreto por el que se nombra a Josep Tarradellas presidente de la Generalitat. Archivo de Salvador Sánchez-Terán, Carpeta: «De Franco a la Generalitat. Cap. 38», Documento 1254.

57 SÁNCHEZ-TERÁN, Salvador; De Franco...op.cit., p. 297. 
Una vez realizadas las correcciones pertinentes, que afectaban fundamentalmente al papel de las cuatro Diputaciones provinciales catalanas, Sánchez-Terán se desplazó a la Moncloa para entregar al presidente del Gobierno el resultado de los acuerdos con Josep Tarradellas ${ }^{58}$.

El viernes 2 de septiembre los miembros del Gobierno estudiaron el Real decreto-ley, que obtuvo una aprobación de facto. Por la tarde, Landelino Lavilla, José Manuel Otero Novas, Íñigo Cavero, Manuel Jiménez de Parga y Manuel Clavero se reunieron en la sede de la Vicepresidencia con Sánchez-Terán, quien les explicó detenidamente el contenido de las negociaciones ${ }^{59}$. A continuación, el texto recibió sus últimos retoques, mejoras técnicas en las que se puso especial cuidado en «no alterar en nada esencial lo ya pactado ${ }^{60}$. En Barcelona, mientras tanto, se hacía público un comunicado de Frederic Rahola donde se anunciaba el acuerdo con el Gobierno para restablecer la Generalitat. Tal como indicaba el representante de Tarradellas en Cataluña, tan sólo restaba reunir a los parlamentarios catalanes y obtener su conformidad al acuerdo para que este tomara forma ${ }^{61}$.

Precisamente el acuerdo de Perpiñán, último escenario dentro del proceso que permitió restablecer la Generalitat, hizo posible la inclusión de los partidos de Cataluña en la negociación del Real decreto-ley 41/1977. Aunque este episodio se cerró el día 28 de septiembre, sus prolegómenos se desarrollaron a lo largo de todo el mes. En primer lugar hemos de destacar la entrevista que mantuvieron, en el aeropuerto de Orly, Josep Tarradellas y los

58 Ibid., pp. 298-299.

59 ABELLA, Carlos, op. cit., p. 247: «Una reunión previa en casa de Sánchez-Terán con Sureda, Ortínez y Rahola había «pulido» tanto su contenido que el visto bueno del Gabinete fue refrendado por el que después del Consejo dieron Lavilla, Clavero, Otero, Jiménez de Parga e Íñigo Cavero, en una conversación en Castellana 3, sede de la Vicepresidencia del Gobierno».

60 SÁNCHEZ-TERÁN, Salvador; De Franco...op. cit., p. 300.

61 TARRADELLAS, Josep, op. cit., p. 223: «En la reunión celebrada en París, los días 26 y 27 de agosto, entre el presidente de la Generalitat, honorable señor Tarradellas, y el delegado del presidente del gobierno, señor Sánchez-Terán, para el restablecimiento de la Generalitat, se acordó seguir estudiando ciertos aspectos técnicos y jurídicos pendientes de resolución. Esta semana han proseguido las conversaciones que desembocaron el lunes en una conclusión aceptable por ambas partes. El presidente Tarradellas, en cumplimiento de los acuerdos con la Asamblea de Parlamentarios de Catalunya, ha convocado ya a la Comisión Negociadora para una fecha inmediata, a fin de exponerle el contenido de esta conclusión. Así pues, depende de la superación de esta etapa que en el término de breves días Cataluña pueda tener Generalitat». 
parlamentarios catalanes ${ }^{62}$. La finalidad de este encuentro no era otra que dar a conocer los resultados de las negociaciones a los líderes políticos de los diferentes partidos, así como informarles de que esos textos legislativos contaban con el visto bueno del Gobierno de España y de la Generalitat ${ }^{63}$.

En segundo término, dentro de la lógica que venimos defendiendo de tres entes dentro de la negociación, nos referiremos a los contactos que, durante el mes de septiembre de 1977, mantuvieron los parlamentarios catalanes con los representantes del ejecutivo español. Estos se llevaron a cabo fundamentalmente en dos etapas: una reunión celebrada en la vicepresidencia del Gobierno el día 7, y una entrevista con Salvador SánchezTerán el 14. En la primera de ellas, ambas partes valoraban positivamente los acuerdos alcanzados por el Gobierno con el president, así que no consideraban necesario abrir un nuevo proceso negociador. Ahora bien, con el fin de perfeccionar el real decreto-ley, los representantes de los partidos plantearon dos modificaciones al texto legislativo. Estas fueron, fundamentalmente, las que llevaron al segundo encuentro, la entrevista con Sánchez-Terán del día 14 de septiembre ${ }^{64}$.

El encuentro entre Josep Tarradellas, los partidos políticos y Salvador Sánchez-Terán tuvo lugar el 28 de septiembre en la Cámara de Comercio e Industria de Perpiñán ${ }^{65}$. Asistieron, además del president y del propio representante del Gobierno, Frederic Rahola, Jordi Pujol, Macià Alavedra, Heribert Barrera, Antón Cañellas, Carlos Güell, Gregorio López Raimundo, Joan Reventós, Josep Maria Triginer, Carlos Sentís y Josep Verde Aldea $^{66}$. La negociación se prolongó hasta las once de la noche, momento

${ }^{62}$ ABELLA, Carlos, op. cit., p. 248: «La reunión se celebró en una sala del aeropuerto de Orly, y a ella asistieron: Carlos Sentís (UCD), Heribert Barrera (ER), Antón Cañellas (UCD), Gregorio López Raimundo (PSUC), Jordi Pujol (CDC), Joan Reventós (PSC), Ramón Trías Fargas (EDC), Josep Maria Triginer (PSOE) y Josep Verde i Aldea (PSR), que fueron los mismos que dos días después eran recibidos en Castellana, 3, por el vicepresidente Abril, al que acompañaban los ministros de Interior y de Regiones, y Sánchez-Terán».

63 TARRADELLAS, Josep, op. cit., p. 224.

64 SÁNCHEZ-TERÁN, Salvador; De Franco...op. cit., p. 304: «Sólo quedaba una cuestión verdaderamente importante que negociar: la constitución del Consejo Ejecutivo y la presencia, participación o control que los parlamentarios y los partidos políticos tendrían en él»

65 FRAGA IRIBARNE, Manuel, En busca del tiempo servido, Planeta, Barcelona, 1987, p. 93: «Miércoles 28: Tarradellas y otros dirigentes políticos se reúnen en Perpiñán, con el enviado del Gobierno, Salvador Sánchez-Terán, para ultimar negociaciones».

66 PUJOL I SOLEY, Jordi, op. cit., p. 309: «Dos semanas después de la manifestación, el 28 de septiembre, nos encontramos en la Cámara de Comercio de Perpinyà Frede- 
en el que, tras alcanzar un acuerdo, Sánchez-Terán y Josep Tarradellas comparecieron antes los medios:

«Señoras y señores, queremos comunicarles que a las once de la noche el honorable señor Tarradellas, los jefes de los partidos y yo personalmente, como representante del presidente del Gobierno, Adolfo Suárez, hemos llegado a un acuerdo sobre el restablecimiento de la Generalitat» ${ }^{67}$.

A la austera, pero cordial, intervención del representante gubernamental, el president quiso añadir unas palabras cargadas de emotividad:

«Para nosotros, catalanes, hoy es un día realmente histórico, que parecía imposible. El pueblo catalán ha triunfado por su tenacidad y por su fe en Cataluña. Creo que muy pronto veremos la Generalitat restablecida y a su presidente en Cataluña, a vuestro lado. Os agradezco a todos vuestra cordialidad. Permitidme que diga: Visça Catalunya! Y Visça Espanya!» ${ }^{68}$.

En Perpiñán, las tres partes aprobaron, con escasas modificaciones, los textos relativos al restablecimiento de la Generalitat y el nombramiento de Josep Tarradellas como su presidente ${ }^{69}$. También se adoptaron

ric Rahola, delegado de Josep Tarradellas en Cataluña, Macià Alavedra, de EDC, Heribert Barrera, de ERC, Antón Cañellas, de la UCD, Carlos Güell, del Centre Català, Gregorio López Raimundo, del PSUC, Joan Reventós y Josep Maria Triginer, del PSC-PSOE, Carles Sentís, de la UCD, Josep Verde Aldea, del PSC-R, y yo, en nombre de CDC. Laureano López Rodó, el ex ministro de Franco y entonces diputado de Alianza Popular, envió una carta de excusa y apoyo. Nuestros anfitriones fueron Salvador Sánchez-Terán y Josep Tarradellas. Sánchez-Terán, que había abandonado recientemente el cargo de gobernador civil de Barcelona y que era entonces diputado en Madrid por la UCD, había sido el hombre escogido por Suárez para mantener las negociaciones entre Tarradellas y nosotros».

67 ABELLA, Carlos, op. cit., p. 249.

68 TARRADELLAS, Josep, op. cit., p. 228.

69 SÁNCHEZ-TERÁN, Salvador; De Franco...op. cit., p. 308: «En los temas esenciales no se introdujeron modificaciones, pues estaban previamente pactados, aunque hubo algún intento de replantear cuestiones tan trabajosamente acordadas. En el decreto ley sólo se cambió el texto de la disposición final $4 .^{\circ}$ : «La Generalidad provisional restablecida no asume más derechos y obligaciones que los derivados del presente decreto ley». Era una cuestión jurídica y política de gran importancia para unos e irrelevante para otros, pero se trataba de evitar cualquier tipo de reclamación - aunque hubiera prescrito - derivada de la actuación de la Generalitat durante la guerra civil». 
los acuerdos sobre el funcionamiento interno de la institución y la constitución de dos comisiones mixtas encargadas de regular el traspaso de funciones del Estado y de las Diputaciones a la Generalitat ${ }^{70}$. El protocolo de Perpiñán quedó recogido en un comunicado oficial de cinco puntos hecho público tras la comparecencia de Tarradellas y Sánchez-Terán ${ }^{71}$. En su conclusión, el texto incluía el siguiente compromiso:

70 Ibid., p. 309: «El texto del Acuerdo de Perpiñán se perfiló en muchos puntos entre los que cabe destacar por su significación política - y no de simple mejora en la redacción- los siguientes:

- Se adoptó el texto «El Consejo Ejecutivo de la Generalidad provisional estará presidido por el presidente de la Generalidad, que podrá delegar únicamente funciones ejecutivas específicas», que sustituía al precedente «El presidente de la Generalitat, que tendrá la condición de consejero jefe o primer consejero». Se desea dejar en claro que no existía la figura del conseller en cap.

- Los consejeros sin cartera pasaban de ser cuatro a cinco, aceptando la demanda socialista.

- Los restantes consejeros se elegirían «entre personas de reconocida competencia», pero se tachó la expresión «y que no tengan clara significación partidista». Los partidos querían llevar sus hombres al Consell, y en ello ponía especial énfasis el PSUC con el apoyo de los socialistas».

71 Acuerdo de Perpiñán. Archivo de Salvador Sánchez-Terán, Carpeta: «De Franco a la Generalitat. Cap. 38», Documento 1260: «En Perpiñán, a 28 de septiembre de 1977, se han reunido bajo la presidencia del honorable Tarradellas y de don Salvador SánchezTerán, representante del presidente del Gobierno, don Adolfo Suárez, los señores: Frederic Rahola, delegado del honorable señor Josep Tarradellas en Cataluña; Macià Alavedra, de Esquerra Democràtica de Catalunya; Heribert Barrera, de Esquerra Republicana de Catalunya; Antón Cañellas, de Unió Democràtica de Catalunya; Carles Güell, de Centre Catalá; Gregorio López Raimundo, de Partit Socialista Unificat de Catalunya; Jordi Puyol, de Convergència Democrática de Catalunya; Joan Reventós, del Partit Socialista de Catalunya (C); Carlos Sentís, de Unió Centre Democràtic, Josep Mari Triginer, de Federació Socialista de Catalunya (PSOE); Josep Verde Aldea, del Partir Socialista de Catalunya $(\mathrm{R})$.

Todos ellos, en su calidad de diputados y dirigentes de sus respectivos partidos políticos. Esta reunión constituye la culminación del proceso negociador sobre el restablecimiento de la Generalidad provisional de Cataluña, que se inició en Madrid con las conversaciones habidas entre el presidente del Gobierno, don Adolfo Suárez y el honorable señor don Josep Tarradellas, y su comunicado conjunto de 2 de julio último, que prosiguió con los acuerdos redactados en París y Saint-Martin-le-Beau entre don Josep Tarradellas y don Salvador Sánchez-Terán y con las reuniones y proposiciones presentadas al Gobierno por los dirigentes de partidos políticos catalanes. Tras la reunión celebrada se han adoptado por unanimidad los siguientes compromisos:

Primero: todos los representantes dan su conformidad al contenido de los proyectos de disposiciones sobre el restablecimiento de la Generalidad de Cataluña. 
«Todos los reunidos han refrendado los principios básicos que han presidido esta negociación para el restablecimiento de la Generalidad provisional, concretados en los siguientes puntos: a) El principio de la unidad de España y de la solidaridad de todos los pueblos que la integran. $b$ ) El reconocimiento de la personalidad de Cataluña simbolizada en el restablecimiento de la Generalidad provisional. c) El proceso de restablecimiento y desarrollo de la Generalidad provisional, de conformidad con la legislación vigente y sin condicionar la futura Constitución $\gg^{72}$.

Segundo: los partidos y organizaciones políticas firmantes, integradas o directamente relacionados con partidos de ámbito nacional, garantizan el pleno apoyo de estos últimos a los proyectos de disposiciones sobre el restablecimiento provisional de la Generalidad.

Tercero: el Consejo Ejecutivo de la Generalidad provisional estará presidido por el presidente de la Generalidad, que podrá delegar únicamente funciones ejecutivas específicas y estará integrado por:

a) Los dirigentes de los partidos políticos - en número de cinco- con mayor representación de parlamentarios catalanes en las elecciones de 15 de junio de 1977, que tendrán el carácter de consejero sin funciones ejecutivas específicas, con el objeto de expresar el respaldo político de los partidos y su participación, en esta fase transitoria;

b) siete consejeros elegidos entre personas de reconocida competencia en cada materia designados por el presidente de la Generalidad, de acuerdo con los diputados y senadores de Cataluña;

c) los cuatro representantes de las diputaciones provinciales de Cataluña.

Cuarto: en cuanto a las normas reglamentarias de régimen interior de la Generalidad provisional, se establecerá en ellas:

a) La participación de los parlamentarios en el nombramientos y cese de los doce consejeros del Consejo Ejecutivo del modo siguiente: «El nombramiento de los doce consejeros se efectuará por el presidente de la Generalidad provisional de acuerdo con los diputados y senadores de Cataluña».

b) Los parlamentarios serán informados y consultados periódicamente sobre la marcha de los trabajos y actuaciones de la Generalidad provisional.

Quinto: el acuerdo del presidente de la Generalidad provisional con los parlamentarios, a los efectos de aprobación de las normas reglamentarias de régimen interior, quedará limitado a los dos aspectos señalados en el punto cuarto de este acuerdo.

Finalmente, todos los reunidos han refrendado los principios básicos que han presidido esta negociación para el restablecimiento de la Generalidad provisional, concretados en los siguientes puntos: a) El principio de la unidad de España y de la solidaridad de todos los pueblos que la integran. b) El reconocimiento de la personalidad de Cataluña simbolizada en el restablecimiento de la Generalidad provisional. c) El proceso de restablecimiento y desarrollo de la Generalidad provisional, de conformidad con la legislación vigente y sin condicionar la futura Constitución»

72 PUJOL I SOLEY, Jordi, op . cit., p. 310. 
En definitiva, dentro del proceso que permitió el restablecimiento de la Generalitat de Cataluña mediante la aprobación del Real decreto-ley 41/1977, cabe distinguir tres grandes acuerdos. El primero de ellos fue el alcanzado por el president y la Asamblea de Parlamentarios en el mes de julio, por el cual Tarradellas integraba a los partidos políticos en las conversaciones con el Gobierno mediante la formación de la Comisión Negociadora. A su vez, estos reconocían la autoridad de la Generalitat, absteniéndose de tomar la iniciativa por otras vías. El segundo acuerdo, cuyos principales protagonistas fueron Josep Tarradellas y Salvador Sánchez-Terán, permitió que Gobierno de España y Generalitat establecieran un texto legislativo que, si bien con ligeros cambios posteriores, fue la base del Real decreto-ley definitivo. El último hito importante tuvo lugar, como acabamos de comentar, en Perpiñán. El 28 de septiembre de 1977, las tres partes - Gobierno, Generalitat y Asamblea de Parlamentarios - participaron en una reunión conjunta que permitió la publicación del texto legislativo un día después.

Ahora bien, todo el proceso que hemos ido describiendo no llegó a su fin hasta que Josep Tarradellas regresó a Barcelona el 3 de octubre. Ese día, ante una gran multitud congregada frente al palacio de la Generatitat, el president pronunció unas palabras cargadas de emoción, un discurso con el que enterraba cuatro décadas de exilio y planteaba el futuro de Cataluña dentro de la nueva España monárquica y democrática:

«Ciudadanos de Cataluña: ja sóc aquí! ¡Ya estoy aquí! ¡Porque yo también quiero el Estatuto! ¡Ya estoy aquí! Para compartir vuestras penas, vuestros sacrificios y vuestras alegrías por Cataluña ¡Ya estoy aquí! Para trabajar con vosotros por una Cataluña próspera, democrática y pletórica de libertad ¡Ya estoy aquí! Por esta Cataluña que tiene que ponerse a trabajar más que nunca para lograr fuerza y prosperidad. Para que sea un ejemplo para todos los pueblos de España. Para que la unidad que hemos forjado en las horas difíciles de nuestra lucha y que nos ha conducido a la victoria sea más sólida que nunca ¡Ya estoy aquí! Que juntos con todos aquellos, catalanes y no catalanes, que durante tantos y tantos años han luchado para que pudiese llegar este día, este estallido de júbilo y entusiasmo, sepamos hacer, como he dicho antes, más próspera y más fuerte nuestra Cataluña. Ciudadanos de Cataluña: permitidme que os pida que en estos momentos de júbilo tengamos también la serenidad de reflexionar y ver las graves responsabilidades que pesan sobre nosotros. Creemos que este triunfo lo hemos logrado gracias al sacrificio de tantos 
y tantos ciudadanos que han dado su vida por Cataluña. Ciudadanos de Cataluña: quisiera que en estos momentos de gozo y responsabilidad pensaseis que tenemos otros deberes fuera de Cataluña. Nosotros tenemos que ser la avanzada del bienestar, de la prosperidad y de la democracia de todos los pueblos de España. Y para terminar, permitidme que os diga que en el fondo de mi corazón brota el más profundo reconocimiento por vuestra fidelidad, por vuestra fe en nuestro pueblo, en la libertad y en la democracia ¡Muchas gracias a todos! Visça Catalunya!» ${ }^{73}$.

\section{Conclusiones}

Una de las principales características del proceso que llevó al restablecimiento de la Generalitat de Cataluña fue, sin lugar a dudas, el consenso. Las tres partes implicadas - Gobierno de España, Generalitat y partidos políticos catalanes - sellaron, después de varios meses de negociaciones e intensas conversaciones, un pacto político y legislativo que, por sus consecuencias, ha de situarse entre los episodios más importantes de la Transición. Además, tal como se indicaba al comienzo del texto, el Real decreto-ley 41/1977 hizo posible el inicio de la descentralización a través de las preautonomías y, tras la aprobación de la Constitución de 1978, con las autonomías. Por tanto, nos encontramos ante una operación política que ha tenido profundas consecuencias en la España actual.

Ahora bien, sería un error considerar este hecho únicamente dentro de los estrechos límites del cambio acaecido tras la muerte del general Franco. La propia persona de Josep Tarradellas, depositario de un legado institucional durante varias décadas de exilio, nos habla de una realidad que hunde sus raíces en un periodo anterior: la Segunda República. El retorno de la Generalitat de Cataluña ha de considerarse, en cierto modo, un símbolo de la reconciliación entre vencedores y vencidos. Esta afirmación viene respaldada por el hecho de ser la única institución republicana restablecida durante la Transición. Ningún político, salvo Josep Tarradellas, retornó a España desde el exilio para ocupar un cargo público sin necesidad de elecciones. Es importante tener en cuenta esta última cuestión, pues la legitimidad del president no era democrática, sino histó-

73 TARRADELLAS, Josep, op. cit., p. 230. 
rica. Y, como es evidente, esa historia nos lleva directamente un periodo anterior al decreto de 5 de abril de 1938 por el cual se derogaba la Generalitat. De hecho, el Real decreto-ley de 1977 comenzaba precisamente eliminando esa disposición legal.

Cabe preguntarse ahora porqué sólo se concedió ese privilegio a la institución de autogobierno catalana y no a otras que, al igual que ella, mantenían su actividad en el exilio. La primera razón ha de buscarse en el propio Josep Tarradellas, en su clarividencia y tenacidad. El president buscó tender puentes con el Gobierno de España prácticamente desde el comienzo de la Transición, y lo hizo desde la perspectiva adecuada: el reconocimiento de los poderes del Estado y la búsqueda de la reconciliación. Además, al haber atraído hacia sí a la oposición nacionalista, logró convertirse en un interlocutor necesario para solucionar la cuestión catalana. Todo esto, unido a su capacidad para levantarse después de cada decepción, le permitió alcanzar el objetivo que anhelaba.

Otro elemento que ayudó al retorno de Josep Tarradellas fue la ausencia de una autoridad política que ocupara un cargo similar en Cataluña. Mientras que el hipotético retorno de un presidente de la República o un presidente del Gobierno en el exilio era imposible por la presencia en España de personas que ocupaban la Jefatura del Estado y del Consejo de Ministros, el restablecimiento de la Generalitat no encontraba ese obstáculo. Desde luego, la tarea no resultaba sencilla, pero, a diferencia de otras, al menos era viable. Llegados a este punto, ha de plantearse porqué no se llevó a cabo una operación similar con el lehedakari Aguirre. Tanto en las memorias de Josep Tarradellas como de Marcelino Oreja, encontramos propuestas en ese sentido. Sin embargo, nunca llegaron a materializarse debido a la conflictiva situación que vivía el País Vasco. Además, a diferencia del president, Aguirre no contaba con el apoyo de todos los grupos políticos vascos.

El tercer factor a tener en cuenta nos lleva a un periodo histórico que va más allá de la Segunda República. La intervención de Juan Carlos I en el restablecimiento de la Generalitat no supuso únicamente una reconciliación con el periodo republicano, sino con la Cataluña a la que los Borbones habían privado de sus instituciones históricas. El Rey desempeñó un papel bastante discreto a lo largo de todo el proceso, pero sin duda decisivo. Sólo intervino de manera directa en tres ocasiones: la iniciativa de la entrevista de febrero de 1976, su placet a la visita del teniente coronel Casinello a Tarradellas en Saint-Martin-le-Beau, y su encuentro con este último en junio de 1977. Es decir, Juan Carlos I participó de manera activa en la organi- 
zación de los dos primeras visitas de representantes del Gobierno al presidente de la Generalitat. Además, en el viaje de Tarradellas a Madrid, su intervención salvó una operación política en estado crítico tras la entrevista con Suárez. En definitiva, podemos afirmar que todas las intervenciones del Rey en el restablecimiento de la Generalitat fueron a favor del proceso.

Un repaso al proceso político que dio lugar al Real decreto-ley 41/1977 estaría incompleto sin un breve análisis de la labor desempeñada por el presidente del Gobierno. Los acontecimientos que acabamos de relatar nos dejan algunos de los rasgos más característicos de Adolfo Suárez. El primero de ellos, sin lugar a dudas, su capacidad para adaptarse, para reconocer que estaba equivocado y tomar la senda correcta. En segundo término, la importancia que daba a las encuestas y a los resultados electorales. De hecho, fueron los comicios de junio de 1977 los que le llevaron a cambiar de opinión sobre Josep Tarradellas. Por último, su sentido práctico que, si bien en numerosas ocasiones fue su aliado, estuvo a punto de echar por tierra la operación en su primer encuentro con el president. En un principio, Suárez tenía serias dificultades para percibir la importancia histórica del retorno de Tarradellas, que veía únicamente como una oportunidad para resolver un problema político. Ahora bien, a favor del presidente hemos de decir que en todo caso hubiera sido muy complicado restablecer la Generalitat antes de las primeras elecciones democráticas. Por una parte, Adolfo Suárez tenía abiertos varios frentes de ámbito nacional que le impedían hacerse cargo de una nueva operación política. Por otra, tras la aprobación de la Reforma Política, la disolución del aparato del Movimiento Nacional y la legalización del Partido Comunista, el presidente no podía permitirse un nuevo enfrentamiento con los sectores más conservadores. Tuvo que llegar el triunfo electoral de junio de 1977 para que Suárez, con el crédito político que otorgan las urnas, asumiera el reto lanzado por Tarradellas.

\section{Bibliografía}

Abella, Carlos, Adolfo Suárez, el hombre clave de la transición, Madrid, Espasa, 2006.

Alonso-Castrillo, Silvia, La apuesta de centro. Historia de la UCD, Madrid, Alianza Editorial, 1996.

BENET, Josep, El president Tarradellas en els seus textos (1954-1988), Barcelona, Empuries, 1992. 
BRICALL, Josep Maria, Memòria d'un silenci: El govern Tarradellas (1977-1980). Una Certa Manera De Fer Política, Barcelona, Rosa del Vents, 2003.

CACiAGLi, Mario, Elecciones y partidos en la transición española, Madrid, CIS, 1986.

CARR, Raimond y FusI, Juan Pablo, España de la dictadura a la democracia, Barcelona, Planeta, 1979.

Fraga IrIBARne, Manuel, En busca del tiempo servido, Barcelona, Planeta, 1987.

FUENTES ARAGONÉS, Juan Francisco, Adolfo Suárez. Biografía política, Barcelona , Planeta, 2011.

GarCía CotARelo, Ramón, Transición política y consolidación democrática. España, 1975-1986. Madrid, CSIC, 1992.

González Clavero, Mariano, Pérez López, Pablo y Pelaz López, José-Vidal, Castilla y León en democracia. Partidos, elecciones y personal político (1977-2007), Salamanca, Junta de Castilla y León, 2007.

Lamelas, Antonio, La Transición en Abril, Barcelona, Ariel, 2004.

Ministerio de Relaciones con las Cortes de la Secretaría de Gobierno, 1812-1992: el arte de gobernar: historia del Consejo de Ministros y de la Presidencia del Gobierno, Madrid, Ministerio de Relaciones con las Cortes y de la Secretaría del Gobierno, 1992.

Molinero, Carme y Ysàs, Pere, La cuestión catalana. Cataluña en la transición española, Barcelona, Barcelona, 2014.

Osorio, Alfonso, Trayectoria política de un ministro de la Corona, Barcelona, Planeta, 1980.

Powell, Charles, Juan Carlos, un rey para la democracia, Barcelona, Ariel, 1995.

Powell, Charles y Bonnin, Pere, Adolfo Suárez, Barcelona, Cara\&Cruz, 2000.

Powell, Charles T., España en democracia, 1975-2000. Las claves de la profunda transformación de España, Barcelona, Plaza \& Janés, 2001.

PORCEl, Baltasar, Conversaciones con el honorable Tarradellas, Barcelona, Plaza\&Janés, 1977.

PREgo, Victoria; Así se hizo la Transición, Barcelona, Plaza\&Janés, 1995.

Prego, Victoria, Diccionario de la Transición, Barcelona, Plaza \& Janes, 1999.

Pujol I Soley, Jordi, Historia de una convicción. Memorias (1930-1980), Barcelona, Destino, 2007

REDERo SAN RoMÁn, Manuel (Coord.), La transición a la democracia en España, Madrid, Ayer n. ${ }^{\circ}$ 15, 1994.

SÁNCHEZ-TERÁn HERnÁNDEZ, Salvador, De Franco a la Generalitat, Barcelona, Planeta, 1988.

SÁNCHEZ-TERÁn HERnÁndez, Salvador, La Transición. Síntesis y claves, Barcelona, Planeta, 2008. 
SantaCAna, Carles, Josep Tarradellas. L'exili,2 (1954-1977), Barcelona, Edicions DAU, 2015.

Soto CARMONA, Álvaro, La transición a la democracia. España. 1975-1982, Madrid, Alianza Editorial, 1998.

TARRADELlAS, Josep, «Ja soc aquí». Recuerdo de un retorno, Barcelona, Planeta, 1990.

Tarradellas, Josep y Sánchez Cervello, Josep, Los Papeles De Tarradellas: Republica, Exilio Y Transicion, Barcelona, Rosa del Vents, 2005.

Tusell Gómez, Javier y Soto CARmona, Álvaro, Historia de la Transición 1975 1986, Madrid, Alianza Universidad, 1996.

URQuiJo Goitia, José Ramón, Gobiernos y ministros españoles en la Edad contemporánea, Madrid, CSIC, 2001.

\section{Fuentes}

Archivo personal de Salvador Sánchez-Terán Hernández.

- Fondos documentales de su etapa como gobernador civil de Barcelona: carpetas 7 y 28 .

- Fondos documentales de la negociación con Josep Tarradellas: carpetas 37 y 38 .

Arxiu Josep Tarradellas.

- Sèrie 2: exili (1939-1977).

- Sèrie 3: president de la Generalitat (1977-1980).

Entrevistas.

- Rodolfo Martín Villa, 20 de junio de 2012.

- Salvador Sánchez-Terán, 5 de julio de 2012.

- Salvador Sánchez-Terán, 24 de febrero de 2015. 